\title{
Fear-related confirmation bias in children: a comparison between neutral- and dangerous-looking animals
}

Citation for published version (APA):

Dibbets, P., Fliek, L., \& Meesters, C. (2015). Fear-related confirmation bias in children: a comparison between neutral- and dangerous-looking animals. Child Psychiatry \& Human Development, 46(3), 418425. https://doi.org/10.1007/s10578-014-0481-3

Document status and date:

Published: 01/06/2015

DOI:

10.1007/s10578-014-0481-3

Document Version:

Publisher's PDF, also known as Version of record

\section{Document license:}

Taverne

Please check the document version of this publication:

- A submitted manuscript is the version of the article upon submission and before peer-review. There can be important differences between the submitted version and the official published version of record.

People interested in the research are advised to contact the author for the final version of the publication, or visit the DOI to the publisher's website.

- The final author version and the galley proof are versions of the publication after peer review.

- The final published version features the final layout of the paper including the volume, issue and page numbers.

Link to publication

\footnotetext{
General rights rights.

- You may freely distribute the URL identifying the publication in the public portal. please follow below link for the End User Agreement:

www.umlib.nl/taverne-license

Take down policy

If you believe that this document breaches copyright please contact us at:

repository@maastrichtuniversity.nl

providing details and we will investigate your claim.
}

Copyright and moral rights for the publications made accessible in the public portal are retained by the authors and/or other copyright owners and it is a condition of accessing publications that users recognise and abide by the legal requirements associated with these

- Users may download and print one copy of any publication from the public portal for the purpose of private study or research.

- You may not further distribute the material or use it for any profit-making activity or commercial gain

If the publication is distributed under the terms of Article $25 \mathrm{fa}$ of the Dutch Copyright Act, indicated by the "Taverne" license above, 


\title{
Fear-Related Confirmation Bias in Children: A Comparison Between Neutral- and Dangerous-Looking Animals
}

\author{
Pauline Dibbets $\cdot$ Lorraine Fliek $\cdot$ Cor Meesters
}

Published online: 6 August 2014

(c) Springer Science+Business Media New York 2014

\begin{abstract}
The purpose of this study was to examine confirmation bias in children without explicitly inducing fear. Eighty non-clinical children (7-13 years) were shown pictures of a neutral animal (quokka) and two dangerouslooking animals (aye aye and possum). For each animal, levels of perceived fear, threat and request for additional threatening or non-threatening information were obtained. A behavioral approach test (BAT) was included as behavioral measure of fear. The results indicated that the aye aye and possum were rated as more threatening and fearful than the quokka. For the aye aye and possum higher fear levels coincided with search for more threatening than nonthreatening information. This pattern was absent in nonfearful children and for the non-threatening quokka. During the BAT the quokka was more often approached first compared to the aye aye and possum. Our findings suggest that confirmation bias in children can be observed without using verbal fear induction.
\end{abstract}

Keywords Fear - Confirmation bias - Children - Threat . Danger

\section{Introduction}

Fear and anxiety are normal adaptive reactions to (potentially) threatening or harmful stimuli. Identification of these stimuli or situations activates cognitive, affective, physiological, and behavioral processes that foster survival.

P. Dibbets $(\square) \cdot$ L. Fliek · C. Meesters

Clinical Psychological Science, Faculty of Psychology and

Neuroscience, Maastricht University, P.O. box 616,

6200 MD Maastricht, The Netherlands

e-mail: Pauline.Dibbets@maastrichtuniversity.nl
However, in case of an anxiety disorder, these processes are over-activated and no longer adaptive, hindering daily functioning.

Current cognitive models posit that individual differences in threat-relevant information processing are at the center of the onset and maintenance of anxiety disorders (e.g. 1, 2). High-anxious persons display various information processing biases (see for a review 3). A bias that is highly relevant for the onset and maintenance of anxiety problems is confirmation bias. This is the inclined tendency to selectively search for information that confirms the dangerousness of the feared object or situation, while ignoring information that disconfirms threat. Though such a verification strategy has survival value, the lack of searching for alternative, non-confirming information hinders the detection of and adaptation to a safe situation. The results of studies on confirmation bias are in line with the cognitive models on threat-relevant information processing. That is, persons that perceive a stimulus or situation as threatening more often search for information that confirms the dangerousness of the dreaded stimulus than for alternative, disconfirming information. In case of an anxiety disorder such a reasoning pattern logically results in the reinforcement and maintenance of the fear $[4,5]$.

Fear and anxiety problems are not restricted to adulthood. The age of onset of anxiety disorders is typically in childhood or adolescence [8] and anxiety disorders are the most common mental disorders in children [9]. As in adults, high anxiety and anxiety proneness in children are associated with information processing deficits [10-12]. Children with these cognitive biases have a higher chance of developing anxiety disorders, because when these children are presented with ambiguous information, they are more likely to process this information in a threat-relevant way. These cognitive biases can influence several steps of 
information processing. Biased information processing leads to higher levels of anxiety, which in turn enhances the formation of cognitive biases [7].

Recently, researchers have gained interest in fear-related confirmation bias in children. In several experimental studies fear to an unknown, initially neutral, animal (e.g. cuscus) was induced. This was accomplished by (indirectly) providing negative information about the animal [13, 14]. Children who received this negative information more often searched for information that confirmed the dangerousness of the unknown animal than children who received positive information. Additionally, they were less inclined to invalidate their negative view [13-15].

Up to now fear-related cognitive biases in children are effectuated by (indirectly) providing negative information. Providing such information might influence the confirmation bias results due to a memory component. For example, providing negative statements as "the cuscus is dangerous" or "the cuscus will attack you" can result in the confirmation of the statement "if you stroke a cuscus, it will bite you", as the child simply applies the remembered information (but see for additional tests, 13).

However, based on the adult literature, the establishment of a negative view is not a necessary condition to observe confirmation bias. Just the mere perception of threat is already sufficient to activate a threat-confirming strategy (e.g. 4). The current study wants to extend these findings to children and examine whether the mere perception of threat is indeed sufficient to induce a confirmation bias. Therefore, the aim of the present study is to examine confirmation bias in children without providing additional information. Based on the previous studies, we expect that only in case of perceived threat children will show an increased search for threatening information and a decreased search for non-threatening information.

\section{Method}

\section{Participants}

Participants were 80 non-clinical children (41 boys, 39 girls) aged $7-13$ years $(M=10.18, S D=1.51$; age categories: 7 years, $n=7$; 8 years, $n=8$; 9 years $n=4 ; 10$ years, $n=19 ; 11$ years, $n=30 ; 12$ years, $n=11$; 13 years, $n=1)$. Children were recruited from four regular primary schools in the Netherlands. All children had the Dutch nationality. Of the parents, the majority was Dutch $(>66 \%)$, $10.6 \%$ had the Turkish nationality, $13.8 \%$ the Moroccan nationality and the remaining parents had a diversity of nationalities (e.g. Slovenian, Belgian, German, English, American, Indonesian, Gambian, Afghan and Somalian). Informed parental consent was obtained by sending parents an information letter concerning the experiment with an informed consent. Note that only children without anxiety problems and without previous or current psychological anxiety treatment were allowed to participate. The experiment was approved by the Ethical Committee Psychology at Maastricht University (approval code: ECP-110).

\section{Material}

\section{Animals}

The three animals used for the present study were selected via a pilot study ( $n=14,6$ different animals). As a neutral stimulus a full color picture of an existing unknown Australian marsupial, the quokka, was used [6]. As potentially dangerous stimuli a color picture of an aye aye, a lemur from Madagascar, and of an angry possum, an Australian marsupial were used (see Fig. 1). The latter picture was included to ensure that at least one of the two dangerous animal pictures was perceived as threatening. The pictures $\left(163 \mathrm{~cm}^{2}\right)$ were printed on a separate paper and labeled with the species name.

\section{Fear Survey Schedule for Children-Revised (FSSC-R)}

The overall level of fear vulnerability was measured with a shortened version of the Fear Survey Schedule for Children-Revised (FSSC-R, 16). The FSSC-R is a 25-item selfreport questionnaire using a 3-point response scale of "no fear", "some fear" or "a lot fear". The questionnaire consists of five subscales ( 5 items per scale): fear of failure and criticism, fear for the unknown, fear for animals, fear of danger and death and medical fears. The total score can be determined by summing up all scores and ranges from 25 to 75 . In the present study Cronbach's alpha was .88, indicating good reliability.

\section{Threat Attitudes Towards The Animals}

Visual Analogue Scales (VASs, $100 \mathrm{~mm}$, printed on paper) were used to measure the threat attitudes of the children towards the target animals. The VASs were accompanied by a picture of the concerning animal. For each animal a total of four VASs was displayed: three concerning threatrelated characteristics of the animal (i.e. perceived dangerousness, likelihood of biting a person and amount of fear encountering the animal) and one referring to a positive, non-threatening characteristic (i.e. perceived kindness). The child was invited to mark the characteristics of each animal. Total threat attitude towards an animal was calculated by averaging only the threat-related items as for each animal Cronbach's alphas increased after deleting the positive (reversed) item, alpha's $>.73$. 

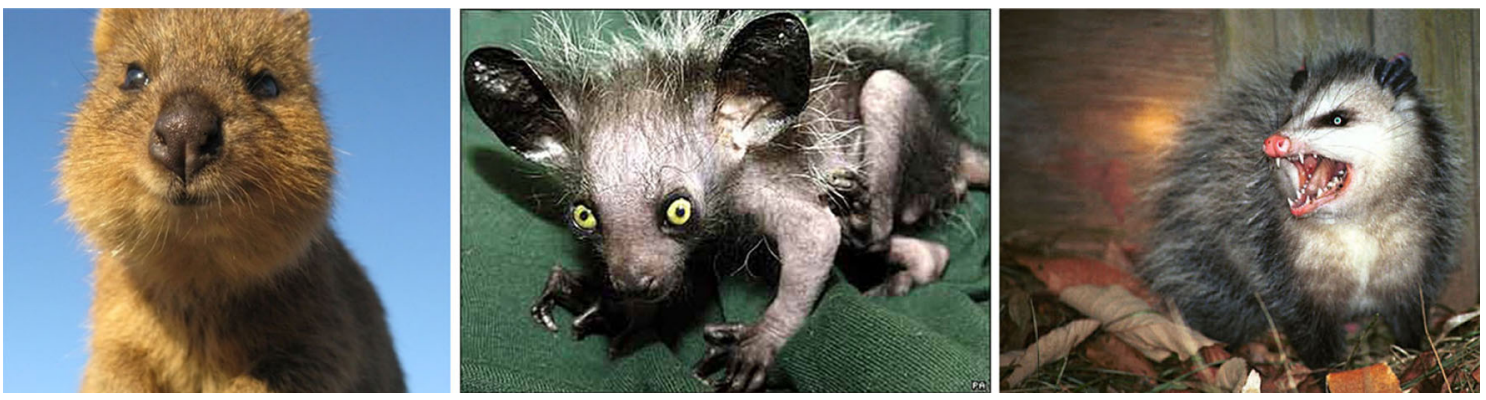

Fig. 1 Picture of the quokka (left), aye aye (middle) and possum (right)

\section{Fear Beliefs Questionnaire (FBQ)}

Three separate Fear Beliefs Questionnaires, FBQs, were used; one for the quokka, one for the aye aye and one for the possum (cf. 13). A picture of the concerning animal accompanied each questionnaire. The questionnaire consists of 10 items to measure the amount of fear for that particular animal. For example: "Would you find it scary to touch a quokka?" or "Do you think that an aye aye will bite you?". Items have to be rated on a 5-point Likert scale by checking the box accompanying one of the following options: $1=$ No, not at all, $2=$ No, not really, $3=$ Yes, maybe, $4=$ Yes, probably, and $5=$ Yes, definitely. Per animal a total fear score can be calculated by summing the ratings on all items (range 10-50). Additionally, to test foreknowledge about the animals, the child was asked whether he/she was familiar with the animal. Three openend options were provided: "No, but I think that this is a(n)...", "Maybe, I think that this is a(n)..." and "Yes, I know this is a(n)...". Cronbach's alphas of the quokka, aye aye and possum FBQ were $.89, .93$ and .90 , respectively.

\section{Confirmation Bias}

The Search for Additional Information Scale (SAIS) is frequently applied in children as a measure of confirmation bias (e.g. 13, 15). Children were asked what kind of additional information they would like to know about each animal. For each animal a list of 14 statements was provided; half of the statements referred to threatening information (e.g. "I would like to know more about the way the quokka kills his prey") and half of the statements concerned non-threatening information (e.g. "I would like to know where the possum sleeps"). The order of threatening and non-threatening statements was at random. Children were asked to indicate for each statement how much they wanted to know about that specific topic on a 5-point Likert scale (range $1=$ nothing to $5=$ everything), resulting in a total score for additional information about non-threat (7-35) and threat (7-35) information per animal. For the
Table 1 Stepwise hierarchy during the behavioral approach test

1. Child grasps food (at $5 \mathrm{~m}$ distance)

2. Child walks towards the animal

3. Child passes 3-m line

4. Child passes 1-m line

5. Child walks towards the box and observes the animal

6. Child walks towards the box, touches the cage and observes the animal

7. Child walks towards the box and raises the wire netting

8. Child walks towards the box, raises the wire netting, places the food cup in the box at a certain distance from the animal

9. Child walks towards the box, raises the wire netting, places the food cup close to the animal in the box

quokka Cronbach's alphas were .88 and .81 , for the aye aye .88 and .85 , and for the possum, .87 and .81 , respectively.

\section{Behavioral Approach Test}

The behavioral approach test (BAT) was carried out to assess approach and avoidance behavior. The (mock) animals were housed in a cardboard box covered by a lid of wire netting. The animal was hidden underneath sawdust and hay. The child was given a food cup filled with seeds and grain and invited to open one of the cages and to feed the animal. A stepwise fear hierarchy was made to record approach behavior (see Table 1). After placing the food cup into the cage, the amount of experienced distress during feeding was recorded using a VAS. This procedure was repeated for the remaining two animals. The order in which the animals were fed and the completed steps of the hierarchy were noted down.

\section{Procedure}

All children were tested in their classroom under supervision of two female research assistants. The assistants guided the children through the session by providing instructions, by collectively running through practice items and they ensured that children did not consult each other 
during testing. Children started with the FSSC-R. Next, one of the assistants exemplified the usage of the VAS scales by filling in the temperature of that day on the VAS (anchors: not hot at all and very hot). After this example, the children filled out the VASs concerning the quokka, possum, and aye aye. Subsequently, children completed the FBQs and the SAISs. For the VAS, FBQ and SAIS the order of animal presentation was counterbalanced resulting in three versions. Different versions were provided for children that were seated next to each other. Next, the children were individually guided by one of the assistants to an adjacent room to carry out the BAT. After the BAT the child received information about the animal and left the school (parents were waiting in the schoolyard). The children, parents, and school were debriefed via an information letter.

\section{Missing Values and Statistics}

A total of seven participants omitted one item of the FSSC$\mathrm{R}$, one participant omitted eleven items. Missing items were imputed using the mean of the remaining items of that particular subscale; the participant missing eleven items was discarded from data analyses concerning the FSSC-R. For the threat attitude, one child missed all items of the quokka VAS, the data of this child were discarded from data analyses concerning the quokka VAS. For the SAIS three participants missed one item; this missing value was replaced by the mean of the remaining (non) threat items of that particular animal. One participant omitted four SAIS items (leaving one page blank) and three participants missed 3 items; these participants were excluded from data analyses involving the SAIS-scores.

The questionnaire and VAS data were analyzed parametrically (General Linear Model, repeated measures and Pearson correlations); the BAT order and steps were analyzed by means of non-parametric tests (Friedman Test and Wilcoxon Signed Ranks test). Bonferroni Holm corrections were made in case of multiple or pairwise comparisons. If sphericity assumptions were violated Greenhouse-Geisser corrections were made. The rejection criterion was set at $p<.05$.

\section{Results}

\section{Anxiety Vulnerability}

The overall level of fear as measured with the FSSC-R was $41.99(S D=8.25$, range 26-63). The scores were normally distributed, Kolmogorov-Smirnov, $D(79)=.058, p=.20$. As in previous research, girls displayed higher FSSC-R scores $(M=45.02, S D=7.52)$ than boys $(M=39.04$,
Table 2 Mean scores (SDs) on the questionnaires and tests concerning the animals

\begin{tabular}{|c|c|c|c|}
\hline & Quokka & Aye aye & Possum \\
\hline VAS threat attitude & 25.34 (19.02) & $53.58(24.44)$ & $57.99(21.42)^{*}$ \\
\hline FBQ & $19.13(7.32)$ & $32.15(10.36)$ & $31.82(9.66)^{*}$ \\
\hline \multicolumn{4}{|l|}{ SAIS } \\
\hline Non-threatening & $25.22(7.62)$ & $22.32(8.28)$ & $22.90(8.00)^{*}$ \\
\hline Threatening & $25.44(6.69)$ & $24.56(7.74)$ & $24.88(7.14)$ \\
\hline \multicolumn{4}{|l|}{$B A T$} \\
\hline Steps & $8.95(.445)$ & 8.61 (1.77) & $8.61(1.77)^{*}$ \\
\hline VAS score & $35.95(34.44)$ & 38.84 (32.44) & 37.95 (32.16) \\
\hline Order & $1.50(.76)$ & $2.19(.63)$ & $2.29(.82)^{*}$ \\
\hline
\end{tabular}

$V A S$ visual analogue scale, $F B Q$ fear beliefs questionnaire, $S A I S$ search for additional information, $B A T$ behavioral approach test

*Main effect of animal, $p<.001$

$S D=7.94), t$ test, $t(77)=3.43, p=.001$ [e.g. 16]. No effect of age was observed, $r=.074, p=.52$. Note that age also did not significantly correlate with other main task effects, $|r| \mathrm{s}<.21, p \mathrm{~s}>.067$. To control for the observed gender difference, we decided to enter gender as a factor for the remainder of the data analyses ${ }^{1}$.

\section{Threat Attitude Differences Quokka, Aye Aye} and Possum

None of the children correctly identified the animals. The results of the questionnaires and tests can be found in Table 2. First, we assessed if the aye aye and possum were perceived as more threatening than the quokka. A general linear model (GLM) with repeated measures was performed with the VAS scores of the animals serving as within-subjects factor and gender as factor. This analysis revealed a main effect of animal, $F(2,154)=103.19$, $p<.001, \eta \rho^{2}=.57$. Pairwise comparisons indicated that both the aye aye and the possum were perceived as more threatening than the quokka, $p \mathrm{~s}<.001, \eta \rho^{2}=.61$ and $\eta \rho^{2}=.68$, respectively. Though the possum received higher ratings than the aye aye, this difference just felt short of significance, $p=.061, \eta \rho^{2}=.044$. A similar analysis was run for the kindness item. This analysis revealed a main effect of animal, $F(2,156)=76.63$, $p<.001, \eta \rho^{2}=.50$. The quokka was rated as more kind than the aye aye and possum, $p \mathrm{~s}<.001, \eta \rho^{2}=.56$ and $\eta \rho^{2}=.60$, respectively. No difference was observed between the aye aye and possum, $p=.44, \eta \rho^{2}=.008$.

\footnotetext{
${ }^{1}$ Note that similar results were obtained in case gender was not entered as a factor in the analyses.
} 
Quokka

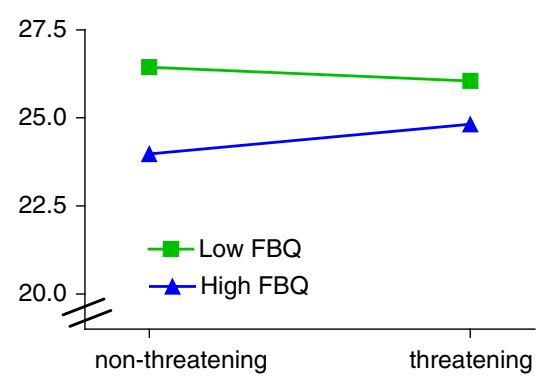

Aye Aye

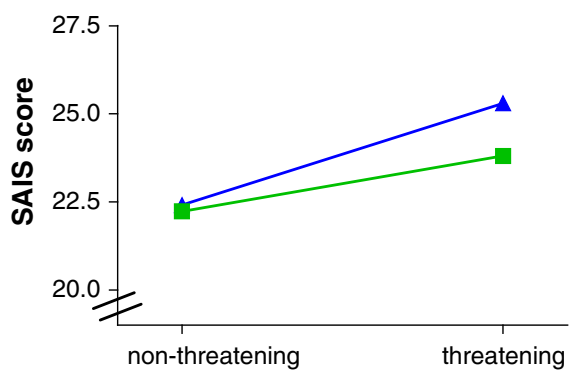

Possum

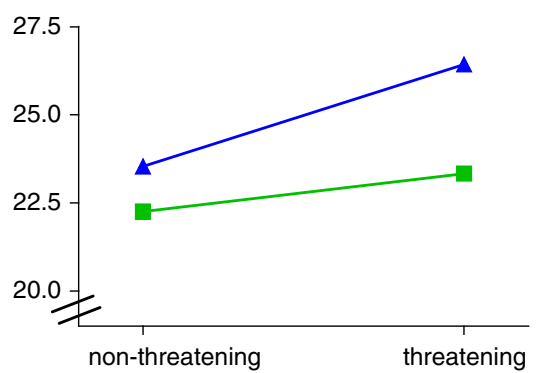

Fig. 2 Information search for high-and low FBQ groups

A similar GLM was run for the FBQ scores. This analysis revealed a main effect of animal, $F(2,156)=118.98$, $p<.001, \eta \rho^{2}=.60$. Both the aye aye and the possum were perceived as more fearful than the quokka, $p \mathrm{~s}<.001$, $\eta \rho^{2}=.66$ and $\eta \rho^{2}=.67$, respectively; no difference was observed between the aye aye and possum, $p=.65$, $\eta \rho^{2}=.003$.

Confirmation Bias: Search for Additional Information

A GLM repeated measures with animal (quokka, aye aye and possum) and search for additional information (SAIS, nonthreatening and threatening) as within-subject factors and gender as factor was run. This analysis revealed a main effect of information, $F(1,75)=6.13, p=.016, \eta \rho^{2}=.077$, and a main effect of animal, $F(2,148)=6.67, p<.005$, $\eta \rho^{2}=.083$. Furthermore, an animal $\mathrm{x}$ information interaction was found, $F(2,148)=5.48, p=.005, \eta \rho^{2}=.069$.

The animal $\times$ information interaction was analyzed further using separate GLMs for each animal. These analyses indicated that for the aye aye participants requested more threatening than neutral information, $F(1,77)=12.61$, $p<.001, \eta \rho^{2}=.14$. A similar pattern was observed for the possum, $F(1,76)=6.85, p<.05, \eta \rho^{2}=.083$.

No such pattern was observed for the quokka, $F<1$. Note that these results cannot be explained by a ceiling effect as all scores significantly fell below the maximum score of 35 , one-sample t-tests, $t$ s $<-11.41$, $p \mathrm{~s}<.001$. These results indicate that perceived threat coincided with a relatively enhanced search for confirming threat-related information. This pattern was not observed for the nonthreatening quokka.

\section{Confirmation Bias and Fear}

Additional GLM repeated measures were run per animal to test the assumption that confirmation bias is specifically observed in case of perceived threat. In each analysis search for additional information (SAIS, non-threatening and threatening) served as within-subject factor, the associated
FBQ score as covariate and gender was implemented as factor. The aye aye analysis revealed a SAIS $\times$ FBQ interaction, $F(1,76)=5.47, p<.05, \eta \rho^{2}=.067$; a similar interaction was observed for the possum, $F(1,75)=4.04$, $p<.05, \eta \rho^{2}=.051$. No such interaction was found for the quokka, $F(1,76)=2.40, p=.13, \eta \rho^{2}=.031$.

The interaction was analyzed further by using a median split on the FBQ data (separately for the aye aye and the possum). Separate GLM repeated measures were carried out for the high-and low-FBQ group (see Fig. 2). The aye aye analysis revealed that the high FBQ group requested more threatening than non-threatening information, $F(1$, $38)=8.19, p<.01, \eta \rho^{2}=.18$, this effect was absent in the low FBQ group, $F(1,37)=2.65, p=.11, \eta \rho^{2}=.067$. The possum analysis revealed a similar pattern, with the high group requesting more threatening than non-threatening information, $F(1,37)=9.86, p<.005, \eta \rho^{2}=.21$, and no significant difference was observed in the low FBQ group, $F<1$.

\section{Behavioral Approach Test (BAT)}

The amount of reported distress (VAS) was analyzed with a GLM repeated measures with animal as within-subjects factor and gender as factor. This analysis revealed no effect, $F<1$. However, positive Pearson correlations were observed between the amount of reported distress and the accompanying FBQ scores; for the quokka $r=.50$, for the aye aye $r=.50$ and for the possum $r=.45, p s<.001$, indicating that higher levels of reported fear on the FBQ coincided with higher distress levels during the BAT.

For the quokka, 79 out of 80 children were able to feed the animal and the remaining child finished step 5 (i.e. child walks towards the box and observes the animal). For the aye aye, 76 children were able to feed the animal, one child finished step 5 , and three children did not dare to approach the animal ( 0 steps completed). This same pattern was observed for the possum. Friedman's Test indicated that the three animals differed concerning the amount of steps, $\chi^{2}(2)=6.00, p<.05$. However, post hoc tests did 
not reveal any significant differences, Wilcoxon Signed Ranks test, $z \mathrm{~s}>-1.73, p \mathrm{~s}>.083$.

Finally, the order in which the animals were approached was analyzed. The quokka was firstly approached by 53 children, whereas the aye aye and possum were the first animal to approach by 9 and 18 children respectively. Friedman's test revealed significant differences between the three animals, $\chi^{2}(2)=26.99, p<.001$. Post-hoc tests indicated that the quokka was more often approached first than the aye aye and possum, $z \mathrm{~s}<-4.21, p \mathrm{~s}<.001$; no difference was observed between the aye aye and possum, $z=-.51, p=.61$. These results indicate that the children were more reluctant to approach the aye aye and possum than the quokka.

\section{Discussion}

The aim of the present study was to examine whether the mere perception of threat, without providing additional information, results in confirmation bias in children. To this end, 80 non-clinical children (age 7-13 years) were shown a picture of an unknown neutral animal, the quokka, and two potentially dangerous-looking animals, the aye aye and an angry possum. Children rated these animals (threat attitude, VAS scores), filled out fear questionnaires concerning these animals (FBQs) and could indicate what kind of additional information, threatening or non-threatening, they would like to receive about the animals (SAIS). At the end the children were invited to feed each animal (BAT). The results indicated that, as expected, the children rated the aye aye and possum as more threatening (VAS) and fearful (FBQ) than the quokka. Concerning the search for additional information, more threatening than non-threatening information was requested for the animals that were perceived as threatening (i.e. aye aye and possum), indicative of confirmation bias; no such pattern was observed for the non-threatening quokka. As expected, this confirmation bias pattern was only observed in children that reported high levels of fear for the aye aye and possum (i.e. high FBQ scores); children with low levels of fear (i.e. low FBQ scores) did not show a discrepancy in search for nonthreatening and threatening information. During the BAT children more often started with feeding the quokka than the two other animals, indicative of avoidance. Furthermore, higher fear belief scores (FBQ) coincided with more self-reported distress during the BAT. These results are in line with our expectations that just the mere perception of threat is sufficient to observe a confirmation bias and that this fear is also expressed in more avoidance.

The results agree with previous research on confirmation bias in children. That is, especially a negative view of an animal coincided with a search for additional threat information (13, 15, see for indirect evidence 17). However, our data on the quokka contradict the results of Muris et al. [13]. In their study a confirmation bias pattern was also observed for the neutral cuscus, even if no negative view was established. In our study, no discrepancy between the search of threatening and non-threatening information was detected. However, the quokka was rated as less threatening as the cuscus (FBQ score, $M=22.18$, $S D=5.52), t(150)=2.88, p=.0046$. A logical explanation is that confirmation bias is only expressed in case fear exceeds a certain threshold, for example if the animal is rated at least as neutral (i.e. an FBQ score close to 30). Additionally, in the study of Muris et al. [13] only one animal was presented, in the current study children received three different animal pictures. It is plausible that children compared the three pictures, resulting in a low level of perceived threat by the quokka.

The BAT data are in line with previous research on fear and avoidance. Higher fear levels coincided with more avoidance [18]. In our study this was most visible in the approach pattern. The least threatening animal, in this case the quokka, was more often approached first compared to the threatening aye aye and possum. An unexpected observation was the lack of a difference between the amounts of reported distress for the animals, though the distress scores did correlate with the FBQ scores. This might be explained by the approach pattern. Children more often selected the non-threatening quokka as the first animal to approach. Feeding a novel animal might elicit distress, even if the animal is rated as non-threatening. After feeding the animal successfully, distress extinction or habituation occurs and subsequent approaches are less fearevoking, resulting in similar ratings across animals. This line of reasoning accords to the literature on habituation and extinction in anxious and non-anxious children. That is, as in our study, in case of no threat non-anxious children showed fast extinction and quickly habituated to potentially or previously harmful stimuli [19]. In case of increased vulnerability or clinical anxiety the children displayed increased responding during a safe situation [19, 20]. Such impaired safety signal learning may be a risk factor for anxiety disorders in adulthood. An option for future studies could be to compare fear behavior and confirmation bias in anxious and non-anxious children.

One point that deserves attention is the confirmation bias patterns observed across animals. The bias was merely caused by a (relative) decrease in search for non-threatening information rather than an increase in the search for threatening information. This mainly reflects the absence of searching for alternative, non-confirming information. Such strategy of course hinders the adjustment of a negative view into a more positive or neutral view. In the study by Muris et al. [13] confirmation bias was mainly observed 
as an increased search for information in case negative or ambiguous information about the neutral cuscus was provided. However, providing positive information resulted in increased search of non-threatening information compared to no information. As such, one can argue that our quokka equaled the positive information condition of the study by Muris et al. [13]. The quokka was indeed rated as more kind than the remaining two animals. Nevertheless, this explanation does not clarify the absence of increased search for threatening information for the aye aye and cuscus. However, when taking a closer look at the level of fear and confirmation bias patterns, we do observe the expected pattern for the aye aye and possum. A high level of self-reported fear coincided with more search for threatening than non-threatening information; in case of a low level of fear no difference between the two types of information was observed. This discrepancy of these patterns was mostly visible as an increase in search for threatening information. These results do support the results of previous studies on confirmation bias in children [13-15, 21].

In the present study no additional information was provided in order to minimize memory bias effects. However, not providing information but only pictures renders the animals ambiguous. From a functional-evolutionary perspective it makes sense to check the dangerousness of novel or ambiguous animals [22]. Such 'better safe than sorry' strategy is then reflected in general high levels of search for threat-related information for all novel animals, even in case an animal is perceived as nonthreatening. In case an animal also entails dangerous features, as is the case with the aye aye and possum, the focus lies on threat-related information, resulting in the ignorance of non-threat-related information.

The present study suffers from several limitations. First, in the current study we only included non-clinical children without anxiety problems. Though we observed an interaction between the perceived threat of each animal and the presence/absence of confirmation bias, this does not imply that similar results will be obtained in a clinically anxious group. Applying the current (adjusted) experimental set-up in clinically anxious children would be a next, logical step. Based on the confirmation bias patterns observed in the high animal-related fear groups of the current study, we expect that a clinical sample will show an even more pronounced confirmation bias. This pattern might even extend to the non-threatening quokka.

Second, as no information was provided, all animals remained ambiguous, even the positively rated quokka. This has the advantage that spontaneous confirmation bias and avoidance patterns can be observed, but the drawback is that such lack of information might trigger a 'better safe than sorry' search strategy. For future studies we would recommend to include two additional groups that receive either positive or negative information.

Third, the current confirmation bias task incorporates threatening and non-threatening statements, but does not comprise safety statements. The lack of safety statements hinders a valid comparison between search patterns for safe and threatening information. Additionally, the child does not have to make a choice between threatening and nonthreatening statements, which might result, for some children, in a general interest for all statements. For future research, we strongly recommend adding safety statements enabling a direct comparison between search for safe, neutral and threatening information. Furthermore, we would recommend adding a second confirmation bias task in which children have to choose between predefined questions (positive, negative or neutral); answers to these questions will always be confirmative [23]. Such task provides more insight in pre-existing fear beliefs and, at the same time, confirms these beliefs [see for a similar approach, [17]. Finally, it would be highly interesting to perform a followup memory test on the children tested. Not only to see which type of information is consolidated in memory, but also to assess the endurance of confirmation bias. Additionally, extending such follow up into a longitudinal study can help to examine the relation between confirmation bias and the development of anxiety disorders [7].

In spite of these shortcomings, the current study does indicate that perceived danger can coincide with confirmation bias. As such, the present data provide support for the notion that just the mere perception of danger is enough to encourage such a strategy. Additionally, we observed that threat-perception results in an initial avoidance of the more dangerous-looking animals. Further studies are necessary to explore the role of threat perception in search strategies in children.

\section{Summary}

Fear-related confirmation bias refers to the tendency to search for information that confirms the dangerousness of a feared object while ignoring disconfirming information. Previous research has examined confirmation bias by (in) directly providing negative information. Providing such information might influence the confirmation bias results due to a memory component. The present study reports the results of a study on confirmation bias in children without explicit fear induction using pictures of a neutral animal (quokka) or of threatening (aye aye and possum) animals. The results indicated that indeed the mere perception of threat is sufficient to result in a confirmation bias. That is, only in case of perceived threat children searched for more threat-related information compared to non-threatening 
information. This pattern was absent in non-fearful children and for the non-threatening quokka. Although study limitations must be considered, such as the omission of safety statements, our data provide more insight in noninduced confirmation bias in children.

Acknowledgments The authors would like to thank Samantha van Hattum, Boukje Nass and Lisanne Peters for their help during dataacquisition. We would also like to thank the schools, parents and children for their contribution.

Conflict of interest The authors declare that they have no conflict of interest.

\section{References}

1. Beck AT, Clark DA (1997) An information processing model of anxiety: automatic and strategic processes. Behav Res Ther 35:49-58

2. Eysenck MW, Derakshan N, Santos R, Calvo MG (2007) Anxiety and cognitive performance: attentional control theory. Emotion 7:336-353

3. Ouimet AJ, Gawronski B, Dozois DJA (2009) Cognitive vulnerability to anxiety: a review and an integrative model. Clin Psychol Rev 29:459-470

4. De Jong PJ, Mayer B, Van Den Hout M (1997) Conditional reasoning and phobic fear: evidence for a fear-confirming reasoning pattern. Behav Res Ther 35:507-516

5. Smeets G, de Jong PJ, Mayer B (2000) If you suffer from a headache, then you have a brain tumour: domain-specific reasoning bias" and hypochondriasis. Behav Res Ther 38:763-776

6. Muris P, Field AP (2010) The role of verbal threat information in the development of childhood fear. "Beware the jabberwock!". Clin Child Fam Psychol Rev 13:129-150

7. Muris P, Field A (2013) Information processing biases. The Wiley-Blackwell handbook of the treatment of childhood and adolescent anxiety, John Wiley \& Sons, Ltd., pp 141-156

8. Kessler R, Ruscio A, Shear K, Wittchen HU (2010) Epidemiology of anxiety disorders. Behavioral neurobiology of anxiety and its treatment, current topics in behavioral neurosciences. Springer, Berlin Heidelberg, pp 21-35

9. Merikangas KR, Nakamura EF, Kessler RC (2009) Epidemiology of mental disorders in children and adolescents. Dialogues Clin Neurosci 11:7-20
10. Waters AM, Lipp OV, Spence SH (2004) Attentional bias toward fear-related stimuli: an investigation with nonselected children and adults and children with anxiety disorders. J Exp Child Psychol 89:320-337

11. Muris $P$ et al (2000) Anxiety and threat perception abnormalities in normal children. J Psychopathol Behav Assess 22:183-199

12. Hadwin J, Frost S, French CC, Richards A (1997) Cognitive processing and trait anxiety in typically developing children: evidence for an interpretation bias. $\mathrm{J}$ Abnorm Psychol 106:486-490

13. Muris P et al (2009) Effects of verbal information on fear-related reasoning biases in children. Behav Res Ther 47:206-214

14. Remmerswaal D, Muris P, Mayer B, Smeets G (2010) "Will a cuscus bite you, if he shows his teeth?" inducing a fear-related confirmation bias in children by providing verbal threat information to their mothers. J Anxiety Disord 24:540-546

15. Muris P, Huijding J, Mayer B, van As W, van Alem S (2011) Reduction of verbally learned fear in children: a comparison between positive information, imagery, and a control condition. J Behav Ther Exp Psychiatry 42:139-144

16. Ollendick TH (1983) Reliability and validity of the revised fear survey schedule for children (FSSC-R). Behav Res Ther 21:685-692

17. Huijding J, Muris P, Lester KJ, Field AP, Joosse G (2011) Training children to approach or avoid novel animals: effects on self-reported attitudes and fear beliefs and information-seeking behaviors. Behav Res Ther 49:606-613

18. Kivlighan DM, Lo Coco G, Gullo S (2012) Attachment anxiety and avoidance and perceptions of group climate: an actor-partner interdependence analysis. J Couns Psychol 59:518-527

19. Liberman LC, Lipp OV, Spence SH, March S (2006) Evidence for retarded extinction of aversive learning in anxious children. Behav Res Ther 44:1491-1502

20. Jovanovic $\mathrm{T}$ et al (2014) Development of fear acquisition and extinction in children: effects of age and anxiety. Neurobiol Learn Mem 113:135-142

21. Remmerswaal D, Huijding J, Bouwmeester S, Brouwer M, Muris P (2014) Cognitive bias in action: evidence for a reciprocal relation between confirmation bias and fear in children. J Behav Ther Exp Psychiatry 45:26-32

22. Öhman A, Mineka S (2001) Fears, phobias, and preparedness: toward an evolved module of fear and fear learning. Psychol Rev 108:483-522

23. Remmerswaal D, Muris P, Huijding J (2014) Parent-offspring transmission of a fear-related cognitive bias: an experimental study. J Clin Child Adolesc Psychol (in press) 